\title{
Levels of customary physical activity among the old and the very old living at home
}

\author{
H M DALlOSSO, K MORGAN, E J BASSEY, S B J EBRAHIM, * P H FENTEM, AND \\ T H D ARIE
}

From the Activity and Ageing Research Group, Departments of Physiology and Pharmacology and of Health Care of the Elderly, University of Nottingham Medical School, Queen's Medical Centre, Nottingham NG7 2UH

SUMMARY With an activity inventory designed specifically for use among elderly people, detailed profiles of customary physical activity were obtained from 507 old (aged 65-74 years) and 535 very old (aged 75 years and over) individuals randomly sampled from the community. Participation in four categories of activity was assessed: outdoor productive activities; indoor productive activities; leisure activities; and walking. Customary engagement in many activities was found to be low, age (old versus very old) and sex being among the most important determinants of participation. The method of assessment is described, and activity profiles normative for older age groups are presented.

While it is widely recognised that activity levels decline with increasing age, the reasons for this decline are inadequately understood, changes in lifestyle and family structure, the effects of disease processes, and a reduction in the physiological capacity for exercise being among the possible explanations. Certainly muscle strength ${ }^{1}$ and cardiovascular and respiratory responses ${ }^{2}$ deteriorate with age, thus reducing the capacity for exercise. Age related deterioration in joint mobility ${ }^{45}$ and in neuromuscular coordination ${ }^{6}$ have also been reported. Many of these factors are either inevitable senescent changes or result directly from ill health. Nevertheless reduced physical activity per se might also account for some of the deterioration in the physical capacity for exercise.

Despite the existence of a number of reports describing levels of customary physical activity within the general population, there is a shortage of normative data describing the elderly. In this paper we define, describe, and discuss levels of customary physical activity within a random sample of 1042 people aged 65 years and over living at home.

\section{Sample and methods}

The survey was conducted within three geographically distinct areas of Nottingham. Collectively, the demographic composition of these three areas, in

* Present address: Department of Geriatric Medicine, Royal Free Hospital, Pond Street, London NW3 2QG terms of age, sex, and the proportion of elderly people living alone, showed no significant departure from the national pattern. ${ }^{78}$

Of 1599 elderly individuals randomly selected from the Nottinghamshire Family Practitioner Committee's records ( 747 aged $65-74 ; 852$ aged $75+$ ), an effective sample of 1299 was available for interview. Causes of loss from the original sample included death, admission to hospital or residential care, and change of address. From the effective sample of 1299 individuals, 1042 agreed to participate in the survey (a response rate of $80.3 \%$ ). The age/sex structure of the interviewed sample is shown in table 1 and did not differ significantly from the original target sample of 1599. Within this stratified sample the age group $75+$ was intentionally over-represented in order to admit

Table 1 Interviewed sample by age and sex

\begin{tabular}{lll}
\hline Age & No. of men & No. of women \\
\hline $65-69$ & 101 & 116 \\
$70-74$ & 122 & 168 \\
$75-80$ & 109 & 165 \\
$80+$ & 74 & 187 \\
Total & 406 & 636 \\
\hline
\end{tabular}

sufficient numbers for both present and prospective analyses. Thus, while the ratio of "old" to "very old" people in the general population is approximately $1 \cdot 62: 1,{ }^{8}$ a ratio of $1: 1$ was aimed for in the present survey. 
Interviews were conducted between May and September 1985 by ten women aged 27-56 years. Interviewer training and the methods of respondent contact to ensure a representative sample are described elsewhere. 910

\section{ASSESSMENT OF CUSTOMARY PHYSICAL} ACTIVITY

In young subjects it is known that the intensity of exercise must exceed approximately $60 \%$ of maximum for at least 20 minutes, at least three times a week, in order to provide enough overload for the improvements collectively attributed to 'training'. In sedentary middle-aged subjects, however, more modest interventions have achieved the required improvement, ${ }^{11}$ and it is possible that fairly low levels of activity may supply sufficient stimulus for the maintenance of physical capacities in the elderly. It was decided in the present study therefore to assess (and define as 'customary') those activities with a probable energy cost of above $2 \mathrm{kcal} / \mathrm{min}$, performed for a minimum of 3 minutes, at least weekly, for at least the previous six weeks.

For convenience, activities were divided into four categories:

1 outdoor productive activities-for example, gardening, house and car maintenance; 2 indoor productive activities-for example, housework, decorating and indoor home maintenance (activities concerned with food preparation were excluded); 3 leisure activities - consisting of active leisure pursuits performed both at and away from home, for example, bowls, cycling, swimming, keep fit excercises (walking was included as a leisure activity if it was described as such (for example, walking the dog); 4 walking - the intention was to record purposeful walking. Only continuous walking that occurred outside the house and garden for a minimum of three minutes was recorded.

In administering the questions on outdoor, indoor, and leisure activities the interviewer first determined whether the respondent's participation in the activity met the criteria for 'customary', and then asked in detail about the frequency and duration of participation. The information reported was recorded as minutes per week. Non participation scored zero.

A different approach was taken in the assessment of walking. The interviewer asked in detail about the walking done yesterday, unless yesterday's walking had been atypical, in which case the respondent was asked about an earlier day (up to a maximum of six days previously). Using a diary recall method ${ }^{12}$ the interviewer went through the day in blocks of time, asking whether and, if so, how much time the respondent had spent walking. Any period of continuous walking of at least three minutes' duration was recorded. The time spent shopping was recorded separately. If the respondent reported no walking, this was recorded as zero.

\section{RELIABILITY AND VALIDITY}

Before the survey a number of pilot studies were conducted to assess the validity and reliability of the items and scales included in the questionnaire. ${ }^{13} 14$ All proved satisfactory in terms of administration time and acceptability to elderly respondents. The reliability of the activity inventory was assessed in a study of 16 elderly women (mean age 67 years) who were interviewed on two occasions separated by a period of two weeks. Significant correlations were obtained between the activity profiles recorded on the two occasions. Mechanical pedometers ${ }^{15}$ were used to validate the questionnaire assessment of walking. Twenty four female members of a keep fit class (mean age 67 years) each wore two pedometers for a period of six days, at the end of which they were interviewed. Significant correlations were found between reported minutes of walking on the sample day and the mean six day pedometer score $(r=0.53, p<0.01)$. The correlation was higher when shopping was excluded $(r=0.68, p<0.001)$.

For the analyses presented here, the physical $\stackrel{\mathbb{2}}{\circ}$ activity data (minutes/day and hours/week) have been $\vec{\sigma} \vec{c}$ recoded into frequencies of participation in one of a $\varnothing \subseteq$ number of blocks of time (eg, less than 2 hours, $2-4$ 응 hours, etc). Statistical comparisons were made using $\overrightarrow{0} \cdot \vec{\varphi}$ the chi-square test or analysis of variance. When, for $\underset{+}{\infty}$ purposes of statistical description, the old (65-74) and very old $(75+)$ subgroups were combined, the older subgroup was appropriately weighted so that the age structure of the combined subgroups approximated that of a true (ie, non stratified) random sample.

\section{Results}

\section{MOBILITY STATUS}

The large majority of the sample was ambulant $(91 \%)$. They walked outside the house and garden at least once every two weeks. This includes those who required a walking aid or walked with difficulty. Six percent of the sample were ambulant but housebound, going out of the house less frequently than once every two weeks. The remaining respondents $(n=26)$ were non-ambulant at the time of interview.

INDOOR, OUTDOOR, AND LEISURE ACTIVITIES The total times (hours/week) reported for indoor productive, outdoor productive, and leisure activities are presented in table 2. Figures 1, 2, and 3 show the frequency of participation in the three categories of activity within each age and sex subgroup when the data are considered in the appropriate blocks of time. 
Table 2 Customary levels of participation in productive and leisure activities (hours/week) by age and sex

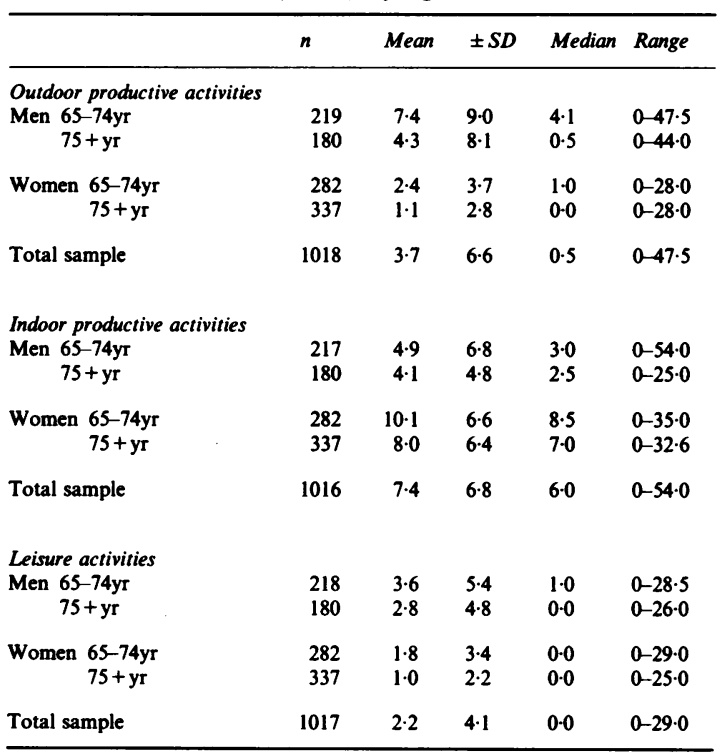

Data are missing for 24 respondents (outdoor activities), 26 respondents (indoor activities), and 25 respondents (leisure activities).

The distributions for all three activities show that individuals tend to cluster at the lower end of the range, a relatively large proportion of respondents having zero scores for that activity (with the exception of indoor activities among women; fig 2a). However, rather than indicating the existence of a single sedentary group, the high proportion of zero scores seems to result mainly from selective participation. Thus, when these activities are considered collectively zero becomes the least probable score for each age and sex subgroup.

Indoor activities were the most frequently reported, $86 \%$ of the sample performing some indoor activities. Overall, $95 \%$ of the total time spent on indoor activities comprised housework, the remaining time being devoted to home maintenance and decorating. Housework of light (eg, dusting) and moderate (eg, bedmaking) intensities occupied equal amounts of time on average ( $48 \%$ of total housework), with only a small amount of heavy housework (eg, floor scrubbing) reported.

Only $53 \%$ of the sample engaged in outdoor activities, the most frequently reported of which was gardening, accounting for $88 \%$ of the total time. Other outdoor activities reported included car maintenance and house repairs. Half of the total reported time spent gardening was quantified as light gardening (eg, weeding and pruning), with the remaining time spent on moderate (eg, electric lawn-mowing and hoeing) and heavy (eg, digging) gardening activities.

Leisure activities were least frequently reported; $47 \%$ of the sample participated in some form of leisure activity with a mean time for the sample of $2 \cdot 2$ hours/week. The individual leisure activities most frequently reported were social walking $(22.4 \%)$, various stretching exercises $(18.8 \%)$, walking the dog $(6.9 \%)$, cycling $(5.5 \%)$, dancing $(3.3 \%)$, and playing bowls $(2 \cdot 1 \%)$. Other leisure activities (including swimming, golf, and fishing) were reported by less than $2 \%$ of the sample.

Significant sex differences were present for all three activity categories, the men participating more in the outdoor $\left(\chi^{2}=119.7, \mathrm{p}<0.0001\right)$ and leisure activities $\left(\chi^{2}=66 \cdot 1, p<0.0001\right)$ and the women participating

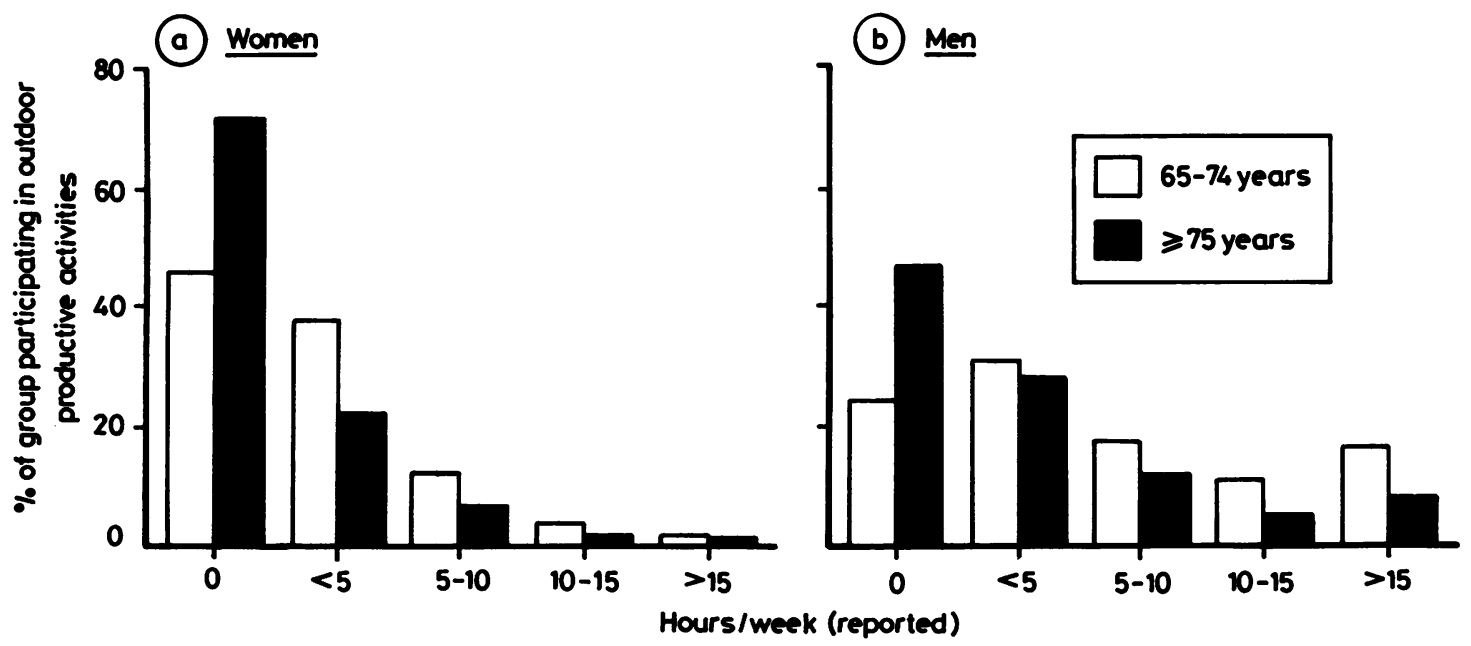

Fig la and b Percentage of group participating in outdoor productive activities 


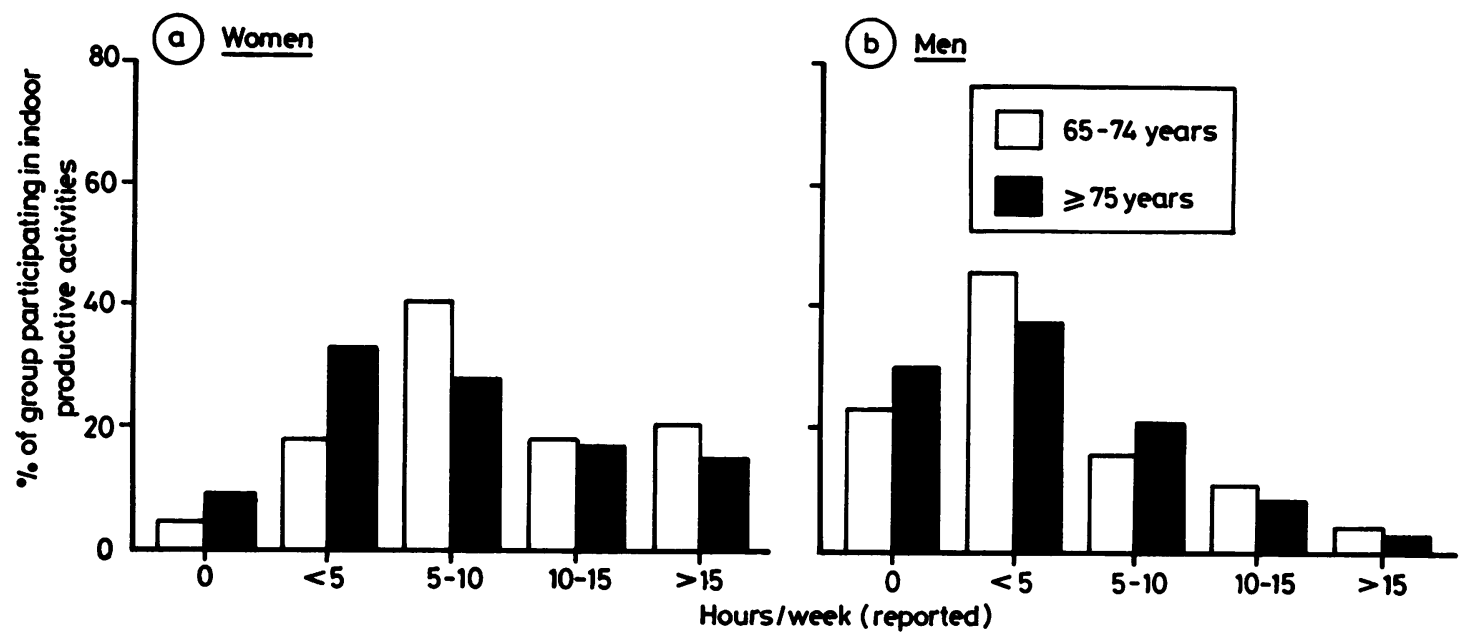

Fig $2 a$ and $b$ Percentage of group participating in indoor productive activities
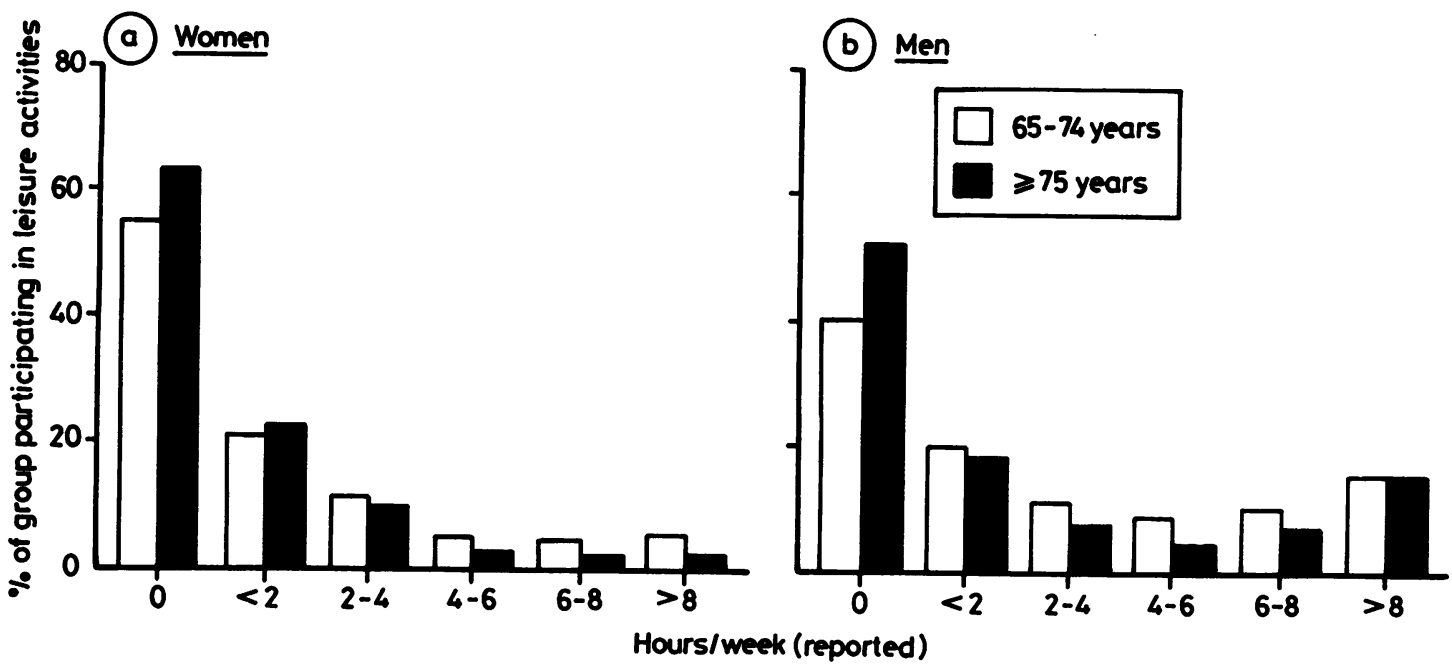

Fig 3a and b Percentage of group participating in leisure activitites

more in the indoor activities $\left(\chi^{2}=153.9, \mathrm{p}<0.0001\right)$. These differences persisted when the old (aged 65-74) and the very old (aged 75+) subgroups were considered independently.

A significant influence of age was found in two of the activities, the younger subgroup reporting more outdoor $\left(\chi^{2}=74.9, \mathrm{p}<0.0001\right)$ and leisure activities $\left(\chi^{2}=21.5, p<0.001\right)$. Controlling for sex, the age difference in the leisure activities was present only for the women $\left(\chi^{2}=13.9, p<0.05\right)$. There was a similar age/sex influence on the amount of indoor activity reported; while this category of activity showed no significant age difference overall, younger women reported higher levels of indoor activity than older women $\left(\chi^{2}=26 \cdot 7, p<0.0001\right)$, an age difference which, as with leisure activities, was not present in the men.

Grouping the activity data into separate blocks for each month of the study, analysis of variance showed no significant 'seasonal' pattern in the three activities (though lower levels of activity would be expected for the winter months. ${ }^{16}$ ) Analysis of variance showed a significant interviewer effect in the time spent on indoor activities $(F=4.47, p<0.001)$, one of the 
interviewers obtaining significantly higher results than the rest of the team (Scheffe Range Test at 1\%).

\section{W A L K I N G}

Two walking scores were computed, viz, total walking and walking exclusive of shopping. These data are expressed in minutes/day. With the exception of eight cases, the respondents reported the amount of walking on the day before the interview. Data are missing for 115 respondents. This is because the interview was discontinued before these questions had been reached $(n=24)$ or, because of short term illness or holidays immediately prior to the interview, it was not appropriate to ask about 'typical' recent walking $(n=15)$. For the purposes of the present analyses a further 76 cases have been removed. For each of these cases the possibility existed that, because of interviewer error, the sample day selected was not typical for that respondent. The age/sex structure of the remaining sample for which walking data are reported $(n=927)$ showed no significant departure from that of the total sample of 1042, and analysis of variance showed no significant interviewer effect in either of the walking scores.

In line with earlier research, ${ }^{12}{ }^{17}$ analysis of variance showed significant day-of-the-week effects in total walking $(F=11.9, p<0.0001)$ and in walking minus shopping $(\mathrm{F}=3.41, \mathrm{p}<0.0025)$, the Scheffe Range Test $(1 \%)$ showing significantly shorter times for Sunday. The frequency with which the respondent reported any walking was greatest on Fridays (77\%) and least on Sundays $(35 \%)$.

Mean reported times (minutes/day) for total walking and walking minus shopping are presented in table 3. Figures 4 and 5 show the distribution of time spent walking when the data are considered in blocks

Table 3 Amounts of walking (min/day) reported for the day preceding the interview

\begin{tabular}{|c|c|c|c|c|c|}
\hline & $n$ & Mean & $\pm S D$ & Median & Range \\
\hline \multicolumn{6}{|l|}{ Total walking } \\
\hline Men $65-74 \mathrm{yr}$ & 206 & $54 \cdot 4$ & $61 \cdot 1$ & 34.0 & $0-276$ \\
\hline $75+y r$ & 164 & 38.9 & $50 \cdot 6$ & $20 \cdot 0$ & $0-260$ \\
\hline Women $65-74 \mathrm{yr}$ & 238 & $54 \cdot 8$ & $62 \cdot 6$ & $40 \cdot 0$ & $0-385$ \\
\hline $75+y r$ & 319 & $26 \cdot 3$ & $40 \cdot 3$ & $00 \cdot 0$ & $0-245$ \\
\hline Total sample & 927 & $45 \cdot 3$ & $56 \cdot 9$ & $25 \cdot 0$ & $0-385$ \\
\hline \multicolumn{6}{|c|}{ Walking minus shopping } \\
\hline Men $65-74 \mathrm{yr}$ & 206 & $37 \cdot 1$ & $45 \cdot 7$ & $20 \cdot 0$ & 0.250 \\
\hline $75+y r$ & 164 & $24 \cdot 7$ & $35 \cdot 4$ & 10.0 & $0-200$ \\
\hline Women $65-74 \mathrm{yr}$ & 238 & $28 \cdot 3$ & 34.9 & 20.0 & $0-195$ \\
\hline $75+y r$ & 319 & $15 \cdot 2$ & $27 \cdot 1$ & 0.0 & $0-245$ \\
\hline Total sample & 927 & $27 \cdot 0$ & 37.5 & $12 \cdot 0$ & $0-250$ \\
\hline
\end{tabular}

Data are missing for 115 respondents. of 30 minutes. Again, both sets of data show a tendency for respondents to cluster at the lower end of the range.

Irrespective of age subgroupings, more walking was reported by the men $\left(\chi^{2}=26.6, p<0.0001\right), 70 \%$ of whom reported some walking compared with $57 \%$ of the women. The younger age group reported more walking than the older age group $\left(\chi^{2}=45 \cdot 3\right.$, $\mathrm{p}<0.0001$ ), a difference that persisted when the sexes were looked at separately. Fifty percent of the older age group reported some walking compared with $70 \%$ of the younger age group. Similar sex and age differences were present in the analyses of walking minus shopping. Grouping the walking data into separate blocks for each month of the study, analysis of variance showed no significant 'seasonal' pattern.

\section{Discussion}

\section{THE SAMPLE}

Short postal questionnaires returned by $42 \%$ of those who refused to be interviewed provided no evidence that, as a group, the refusals were any less healthy or any more or less active than the interviewed sample. Indeed, from pilot studies conducted prior to the survey, ${ }^{13}$ examination of general practitioners' records showed no significant difference between the health status of survey responders and that of age and sex matched controls in the same practice. In terms of health and activity profiles then, we are confident that the present sample is both locally and nationally representative.

\section{RELIABILITY OF THE ACTIVITY DATA}

There exist in the literature few benchmarks against which to compare the present findings. Nevertheless intuitively plausible patterns of customary physical activity within the older and younger subgroups provide considerable support for the reliability of the present data. For example, the age and sex differences are in the expected directions, with a greater participation by the younger age group in all activities. Indoor activities were reported more often by the women, while outdoor and leisure activities were reported more often by the men. Furthermore, high rates of participation in indoor and outdoor activities are unsurprising in a sample of retired people living in the community, a large number of whom lived alone and $85 \%$ of whom had a garden.

Where it has been possible to compare the present results with published data, the agreement has been satisfactory. Levels of participation in leisure activities found in the present study agree well with those reported in the General Household Survey ${ }^{18}$ for the age group 60 years and over, and the data on walking are similar to those reported by Todd and Walker. ${ }^{12}$ 

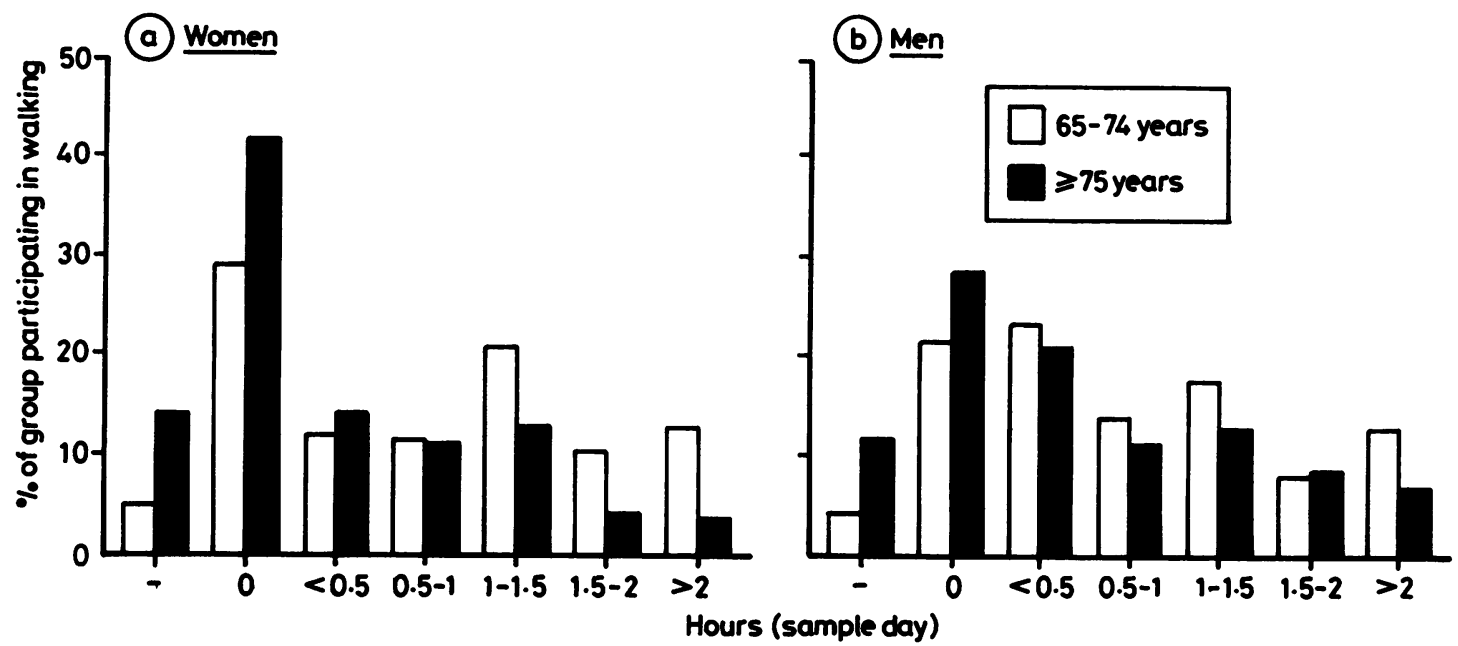

Fig $4 a$ and $b$ Percentage of group participating in walking
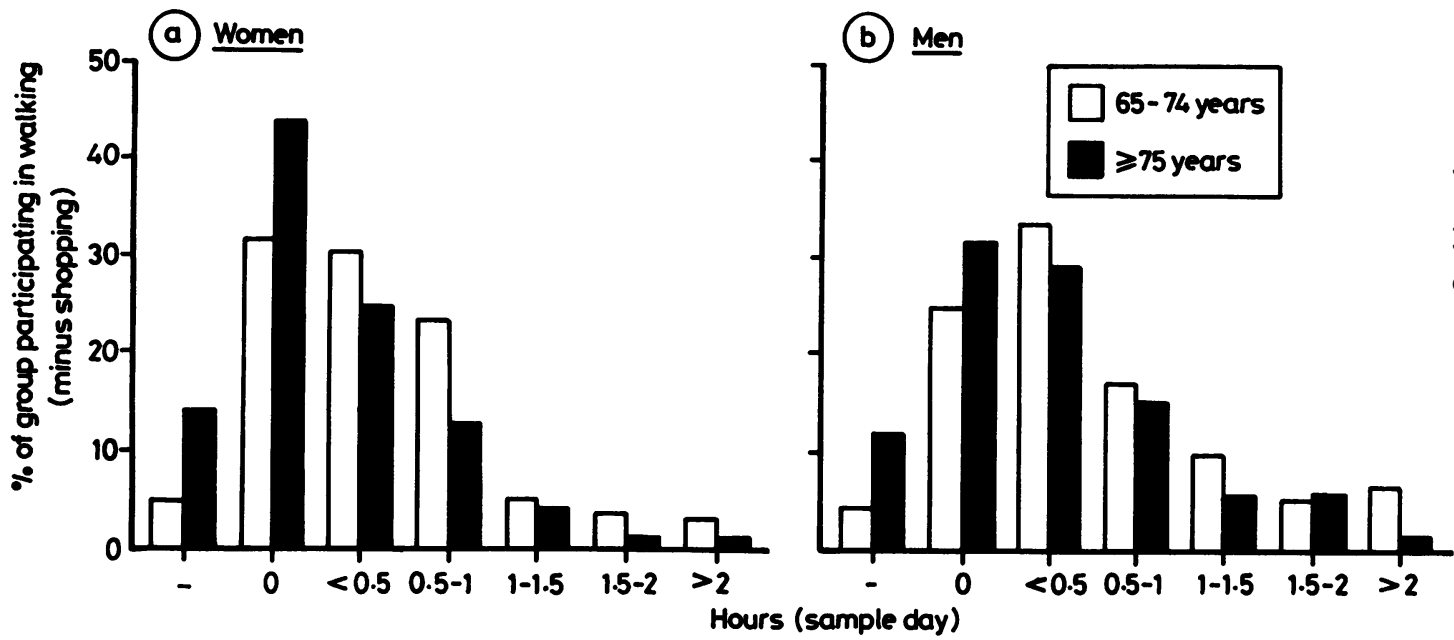

Fig 5a and b Percentage of group participating in walking (minus shopping)

\section{Distribution of activities}

Indoor activities were reported by the largest percentage of the sample, followed by outdoor activities and, finally, leisure pursuits. The indoor activities were made up almost exclusively of light or moderate intensity housework. The pattern of outdoor activities reported was similar, with the large majority of time spent on those of light and moderate intensity. These low participation rates in activities of high intensity may reflect levels of physical incapacity in the elderly. Alternatively, there may in fact be little need for such chores to be performed on a regular basis.
Nearly half the sample $(46 \%)$ took part in some form of leisure pursuit on a customary basis, although the levels of participation in the various individual activities were not high. In Britain, these low rates of participation are typical for all age groups except teenagers. ${ }^{18}$ The leisure activity most frequently reported was walking for pleasure, with stretching exercises (either at home or in organised classes) the second most popular.

The contribution that walking makes to the activity profile of the elderly is further emphasised by the amount of walking reported for the day before the interview. Overall $62 \%$ of the sample reported some 
walking, $29 \%$ walking for more than an hour on this day. Forty per cent of the time reported walking was spent shopping, this being higher for the women $(47 \%)$ than for the men $(35 \%)$.

The present survey provides a valuable profile of customary activity levels among retired and elderly people living at home. Nevertheless, while levels of activity are inextricably linked with levels of functional ability, the cause-effect relationship between these variables remains to be evaluated and will be addressed in future reports.

The Activity and Ageing research group is supported by the Grand Charity.

\section{References}

${ }^{1}$ Asmussen E, Heeboll-Nielsen K. Isometric muscle strength of adult men and women. Communications from the testing and observation institute of the Danish Association for Infantile Paralysis, 1961; publication no 11.

2 Shephard RJ. World standards of cardio-respiratory performance. Arch Environ Health 1966; 13: 665-72.

${ }^{3}$ Binkhorst RA, Pool J, van Leeuwen P, et al. Maximum oxygen uptake in healthy nonathletic males. Arbeitphysiol 1966; 22: 10.

${ }^{4}$ Long C, Krysztofiak B, Zamur I, Lane J, Kochler ML. Visco-elastic characteristics of the hand in spasticity: a quantitative study. Arch Phys Med Rehabil 1968; 49: 677-91.

5 Chapman EA, De Vries HA, Swezey R. Joint stiffness: effects of exercise on young and old men. J Gerontol 1972; 27: 218-21.

${ }^{6}$ Hasselkus ER, Shamber GN. Ageing and postural sway in women. J Gerontol 1975; 30: 661-7.

${ }^{7}$ Office of Population Censuses and Surveys. Census 1981: sex, age, and marital status (Great Britain). London: HMSO, 1983.
${ }^{8}$ Office of Population Censuses and Surveys. Census 1981: persons of pensionable age (Great Britain). London: HMSO, 1983.

${ }^{9}$ Dallosso H, Morgan K, Ebrahim S, Smith C, Bassey J, Fentem $P$, Arie T. Health and contact with medical services among the elderly in Greater Nottingham. East Midland Geographer 1986; 65: 37-44.

${ }^{10}$ Morgan K, Dallosso HM, Arie T, Byrne EJ, Jones R, Waite J. Mental health and psychological wellbeing among the old and the very old living at home. Br J Psychiat 1987; 150: 801-7.

${ }^{11}$ Bassey EJ, Patrick JM, Irving JM, Blecher A, Fentem PH. An unsupervised 'aerobics' physical training programme in middle aged factory workers: feasibility, validation and response. Eur J Appl Physiol 1983; 52: 120-5.

12 Todd JE, Walker A. People as pedestrians. London: HMSO: 1980.

${ }^{13}$ Ebrahim S, Morgan K, Dallosso H, Bassey J, Harries U, Terry A. Interviewing the elderly about their health: validity and effects on family doctor contacts. Age and Ageing 1987; 16: $52-7$.

${ }^{14}$ Morgan K, Dallosso HM, Ebrahim SBJ. A brief selfreport scale for assessing personal engagement in the elderly: reliability and validity. In: Butler A, ed. Ageing: recent advances and creative responses. Beckenham: Croom Helm, 1985; 298-304.

15 Bassey EJ, Dallosso HM, Fentem PH, Irving JM, Patrick JM. Validation of a simple mechanical accelerometer (pedometer) for the estimation of walking activity. Eur J Appl Physiol 1987; 56: 323-30.

16 Yasin S, Alderson MR, Marr JW, Pattison DC, Morris JN. Assessment of habitual physical activity apart from occupation. Br J Prev Soc Med 1967; 21: 163-9.

${ }_{17}$ Abrams M. A survey of the elderly shopper. Mitchum, Surrey: Age Concern Research Unit, 1985.

18 Office of Population Censuses and Surveys (social survey division). General Household Survey. London: HMSO, 1983. 